\title{
PENGEMBANGAN MULTIMEDIA PREZI BERBASIS \\ PROBLEM BASED LEARNING (PBL) PADA MATERI HUKUM-HUKUM DASAR KIMIA KELAS $X$ IPA DI SMAN 1 BUKITTINGGI
}

\author{
Dewi Putri Handayani, Rahadian Zainul* dan Fajriah Azra \\ Jurusan Kimia, FMIPA Universitas Negeri Padang \\ email : rahadianzmsiphd@yahoo.com
}

\begin{abstract}
This research is aimed to produce a prezi multimedia based on Problem Based Learning (PBL) in Basic Law of Chemistry material and to determine the level ov validaty and practicality based on media's function. This research is Researc and Development $(R \& D)$ which applies 4-D madel: define, design, develop, and disseminate. The research is done until development stage. Determining the level of validity and practicality are done by Chemistry lecturer, Chemistry teacher,and students of class XI IPA SMAN 1 Bukittinggi. The research instrument is questionnaire which consists of validity questionnaire and practicality questionnaire. The technic of data collection is done by distributing questionnaire. The data is analyzed by using moment kappa. From the data analysis, it is found that Prezi Multimedia based on Problem Based Learning (PBL) in Basic Law of Chemistry material has moment kappa validity about 0,85 with very high level of validity, moment kappa practicality from teacher's evaluation about 0,86 with very high level of practicality, and moment kappa practicality from student's evaluation about 0,80 with high level of practicality. The learning media that have been developed is proved valid and practical, so it can be used on Chemistry learning process in class X IPA at SMAN 1 Bukittinggi.
\end{abstract}

\section{Keyword - Multimedia,Prezi, Problem Based Learning (PBL), Basic Law of Chemistry, 4-D model.}

\section{PENDAhuluan}

Pendidikan adalah salah satu kebutuhan pokok manusia yang harus dipenuhi oleh Negara, karena kemajuan suatu Negara dapat dilihat dari kualitas pendidikannya. Berbagai upaya telah dilakukan oleh pemerintah untuk mewujudkan kualitas penddidikan yang bagus, antara lain melalui perbaikan sarana pendidikan, perbaikan kurikulum, perbaikan materi bahan ajar, pengembangan, serta pelatihan bagi guru dan tenaga kependidikan lainnya. Sehingga, saat ini, telah banyak teknologi dan aplikasi pendukung yang dikembangkan untuk mempermudah meningkatkan motivasi siswa dalam belajar.

Teknologi digunakan sebagai media pembelajaran, penggunaan media pembelajaran merupakan bagian penting yang harus diperhatikan oleh seorang guru. Media pembelajaran ialah salah satu alternative yang dapat membantu mengatasi masalah belajar sisiwa, karena dengan menggunakan media pembelajaran (contohnya CD interaktif) siswa dapat belajar mandiri, pembelajaran lebih menarik, dan siswa merasa nyaman. Arsyad (2007: 171) menyatakan bahwa multimedia bertujuan untuk menyajikan informasi dalam bentuk yang menyenangkan, menarik, mudah dimengerti, dan jelas.

Hukum-hukum dasar kimia merupakan salah satu materi kimia yang dipelajari di kelas $\mathrm{X}$ semester genap di sekolah menengah tingkat atas. Materi hukum-hukum dasar kimia adalah salah satu materi dasar untuk mempelajari materi selanjutnya seperti perhitungan kimia. Pada materi hkumhukum dasar kimia berisi tentang konsep-konsep dari hukumhukum dasar kimia. Sebagian peserta didik masih kesulitan dalam memahami materi hukum-hukum dasar kimia karena peserta didik masih sulit untuk menemukan konsep sendiri, masih sulit dalam perhitungan, dan sulit menentukan senyawa yang memenuhi hukum-hukum tersebut. Maka diperlukan pemahaman konsep yang mendalam oleh siswa agar dapat memecahkan masalah dalam perhitungan kimia. Materi hukum-hukum dasar kimia bersifat fakta, konsep, prinsip, dan procedural.

Berdasarkan hasil observasi dan wawancara dengan beberapa orang guru kimia serta pemberian angket kepada beberapa siswa di SMAN 1 Bukittinggi, diketahui bahwa sekolah tersebut telah menggunakan kurikulum 2013 dalam proses pembelajaran. Dalam mempelajari materi hukumhukum dasar kimia telah menggunakan bahan ajar seperti buku teks, LKS, dan power point. Setengah dari siswa mengatakan bahwa siswa lebih semangat belajar kimia ketika dalam proses pembelajaran kimia guru menggunakan media pembelajaran yang menggunakan computer. Namun, bahan ajar yang digunakan khususnya bahan ajar yang menggunakan computer (media) belum disusun sesuai dengan tuntutan kurikulum 2013.

Kurikulum 2013 menuntut guru untuk mampu berkreasi dalam memberi hal baru dalam pembelajaran. Dalam pembelajaran tersebut, diterapkan pendekatan saintific. Pendekatan saintific merupakan suatu proses pembelajaran yang menanatang siswa untuk mengembangkan kemampuan berpikir kritis, kreatif dan inovatif. Pendekatan saintific dimaksudkan untuk memberikan pemahaman kepada siswa dalam mengenal, memahami berbagai materi menggunakan pendekatan ilmiah, bahwa informasi bisa berasal dari mana 
saja, kapan saja, tidak tergantung pada informasi searah dari guru (Majid, 2014: 70). Pendekatan saintific menyarankan beberapa model pembelajaran untuk pelaksanaannya yaitu pembelajaran Inquiry Based Learning, Project Based Learning, Discovery Learning dan Problem Based Learning (PBL).

Model pembelajaran yang dapat menuntun siswa untuk mencari tahu informasi adalah pembelajaran berbasis Problem Based Learning (PBL). Pembelajaran berbasi PBL merupakan model pembelajaran yang menjadikan masalah sebagai dasar bagi siswa untuk belajar. Untuk itu dibutuhkan suatu media pembelajaran yang dirancang sesuai dengan kurikulum 2013.

Media pembelajaran yang sering digunakan adalah Power Point. Power Point merupakan sofware presentasi yang disediakan oleh Microsoft Office, sehingga dalam penggunaannya terlebih dahulu komputer pengguna telah terinstal Microsoft Office. Disamping itu ada sofware lain yang dapat digunakan sebagai media pembelajaran yaitu Prezi.

Prezi pun merupakan software presentasi yang juga dirancang agar dapat menampilkan media visual, audio maupun animasi. Prezi dikembangkan pada tahun 2007 dan dipublikasi pada tahun 2009 oleh seorang seniman yang berasal dari Hungaria yaitu Adam Somlai-Fischer dan seorang ahli komputer yaitu Peter Halacsy (Krause, 2014). Prezi memberikan kesempatan kepada pengguna untuk menampilkan informasi dan keterampilan yang tinggi dan tata ruang yang dinamis.

Prezi memiliki zoomable canvas, yang memungkinkan pengguna tidak perlu berpindah dari satu slide ke slide lain. Cukup hanya dengan satu kanvas besar yang bisa menginput gambar, video, teks dan lain-lain. Software Prezi juga dapat menginfut pdf yang menunjang kemudahan untuk menyusun slide presentasi serta dapat diunduh kedalam bentuk file exxecutable (EXE). Selain itu prezi didukung oleh kemampuan zoom in dan zoom out yang berfungsi untuk memperbesar dan memperkecil kanvas sehingga membuat presentasi lebih dinamis dan menarik. Penelitian yang dilakukan oleh Epinur (2014) juga menunjukkan media pembelajaran menggunakan prezi menarik bagi siswa.

Penggunaan Prezi sebagai multimedia yang didalamnya terintegrasi video, gambar dan audio yang penyususnannya disesuaikan dengan sintak PBL diharapkan siswa akan lebih mudah memahami materi hukum-hukum dasar kimia yang disampaikan. Selain itu pembelajaran kimia dengan menggunakan madel Problem Based Learning (PBL) akan meningkatkan minat belajar siswa (Elfina Rahman: 2015).

Berdasarkan penjelasan tersebut, sepengetahuan penulis belum ada yang mengembangkan multimedia berbasis Problem Based Learning (PBL) untuk materi hukum-hukum dasar kimia. Maka penulis tertarik untuk melakukan penelitian Pengembangan Multimedia Prezi Berbasis Problem Based Learning (PBL) pada Materi Hukum-Hukum Dasar Kimia untuk Kelas X IPA di SMA Negeri 1 bukittinggi.

\section{METODE PENELITIAN}

Jenis penelitian ini adalah penelitian pengembangan atau Research and Development (R\&D) yaitu penelitian yang digunakan untuk menghasilkan produk tertentu dan menguji keefektifan produk tersebut. Model pengembangan yang digunakan adalah model 4-D. Model 4-D terdiri dari 4 tahap, yaitu: (1) define (pendefenisisan), (2) design (perancangan), (3) develop (pengembangan) dan (4) disseminate (penyebaran). Penelitian ini dibatasi sampai tahap develop (pengembangan).

Tahap define terdiri dari beberapa langkah, yaitu: (a) analisis ujung depan, (b) analisis siswa, (c) analisis tugas, (d) analisis konsep dan (e) perumusan tujuan pembelajaran. Pada tahap design, dilakukan pembuatan sketsa produk, pemilihan format disuaikan dengan materi, dan pengembangan kerangka. Pada tahap develop, multimedia prezi yang telah dirancang, dinilai kevalidannya oleh beberapa orang validator. Selanjutnya multimedia prezi direvisis berdasarkan saran yang diberikan validator. Multimedia prezi yang sudah direvisis selanjutnya diujicobakan untuk menentukan tingkat praktikalitasnya.

Instrumen yang digunakan dalam menentukan tingkat validitas multimedia prezi adalah angket validasi yang diisi oleh beberapa validator, yaitu dua orang dosen kimia dan dua orang guru kimia SMA. Instrumen yang digunakan untuk menentkan tingkat praktikalitas multimedia prezi adalah angket yang diisi oleh guru kimia dan 30 orang siswa SMA. Validitas dan praktikalitas multimedia prezi dianalisis menggunakan formula kappa cohen.

$$
\text { Moment kappa }(k)=\frac{\rho-\rho_{\mathrm{e}}}{1-\rho_{\mathrm{e}}}
$$

Keterangan:

$k \quad=$ Momen kappa

$\rho_{o}=$ Proporsi yang terealisasi, dihitung dengan cara, jumlah nilai yang diberi oleh validator dibagi jumlah nilai maksimal.

$\rho_{e} \quad=$ Proporsi yang tidak terealisasi, dihitung dengan cara, jumlah nilai maksimaldikurang jumlah nilai yang diberi oleh validator dibagi jumlah nilai maksimal.

Momen kappa $(k)$ berkisar dari 0-1. Interpretasi nilai momen kappa dapat dilihat pada Tabel I.

Tabel I. Interpretasi nilai momen kappa (k)

\begin{tabular}{|c|c|}
\hline Interval & Kategori \\
\hline $0.81-1.00$ & sangat tinggi \\
\hline $0.61-0.80$ & Tinggi \\
\hline $0.41-0.60$ & Sedang \\
\hline $0.21-0.40$ & Rendah \\
\hline $0.01-0.20$ & sangat rendah \\
\hline$\leq 0.00$ & tidak valid \\
\hline
\end{tabular}

\section{HASIL DAN PEMBAHASAN}

A. Hasil 
Hasil penelitian ini adaah produk berupa multimedia prezi berbasis Problem Based Learning (PBL) pada materi hukum-hukum dasar kimia. Tampilan multimedia prezi dapat dilihat pada Gambar 1.
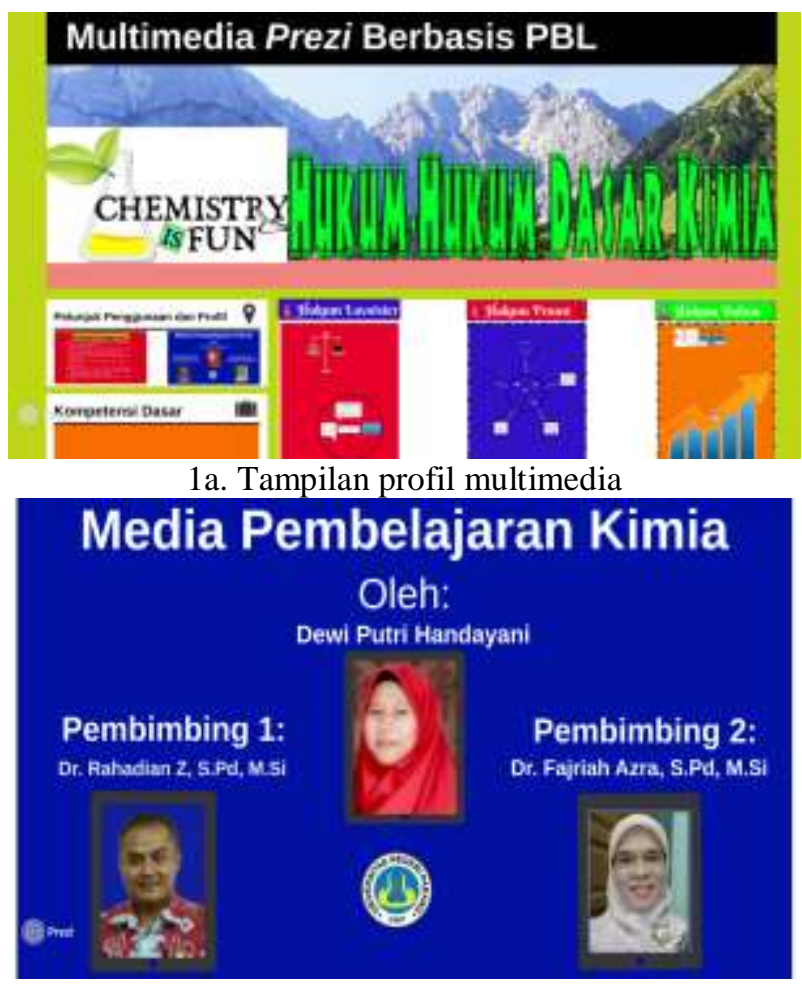

1b. Tampilan profil penulis dan pembimbing

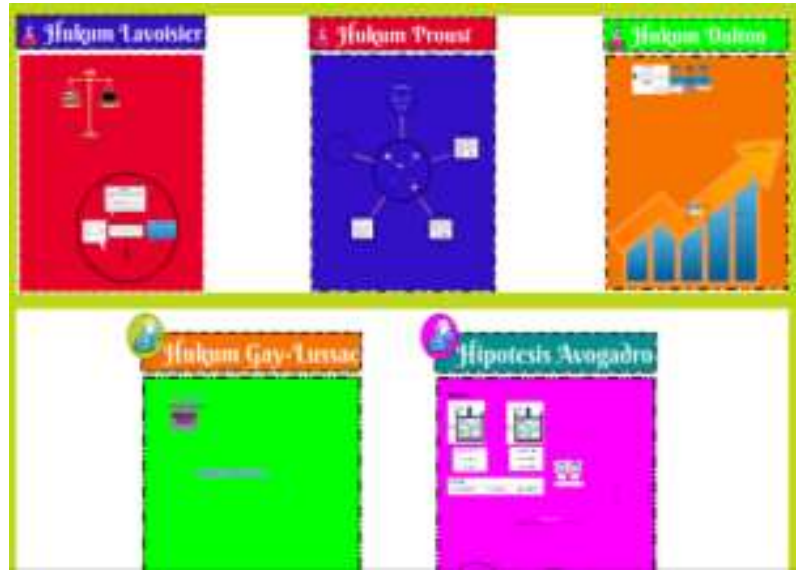

1c. Tampilan materi pembelajaran

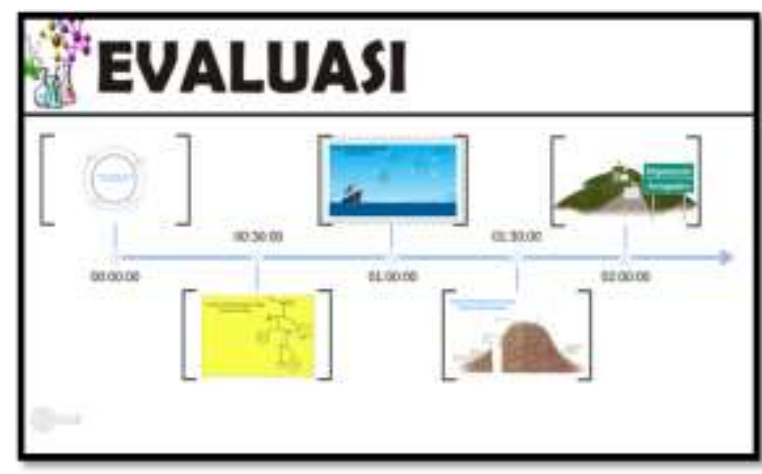

1d. Tampilan soal evaluasi

Gambar 1. Tampilan Multimedia Prezi

Pada tahap develop diperoleh data penilaian validitas dan praktikalitas multimedia prezi berbasis Problem Based Learning pada materi hukum-hukum dasar kimia.

\section{Penentuan Tingkat Validitas}

Tingkat validitas multimedia prezi ditentukan berdasarkan fungsi media yaitu fungsi atensi, fungsi afektif, fungsi kognitif, dan fungsi kompensatoris. Data penilaian validitas multimedia prezi dapat dilihat pada Gambar 2.

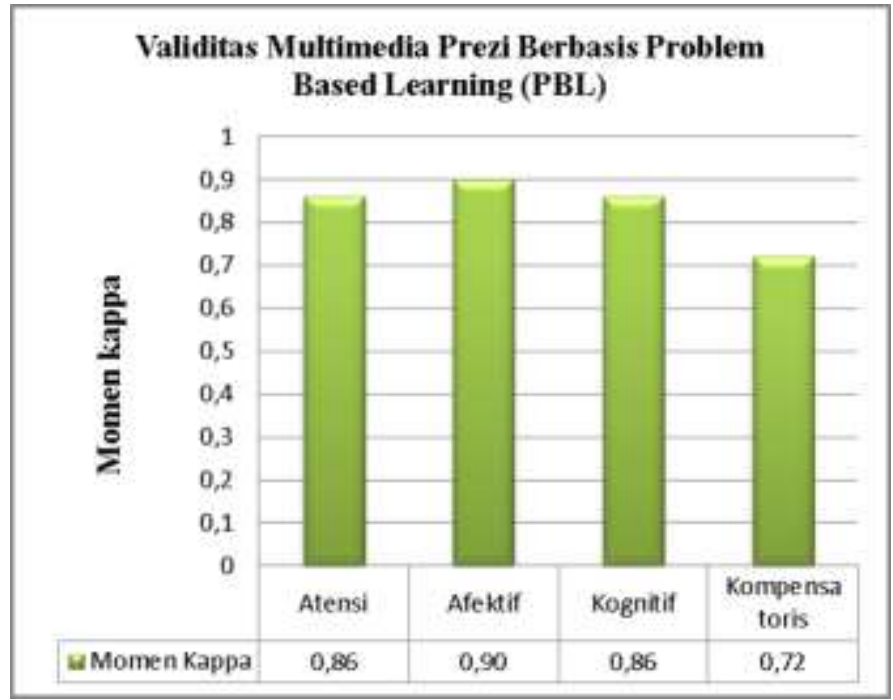

Gambar 2. Hasil Validitas Multimedia Prezi Berbasis Problem Based Learning.

1. Penentuan tingkat Praktikalitas

Data penilaian praktikalitas Multimedia Prezi Berbasis Problem Based Learning diperoleh dari angket guru kimia SMA dan siswa. Data penilaian Guru kimia SMA dan siswa dapat dilihat pada Gambar 3. 


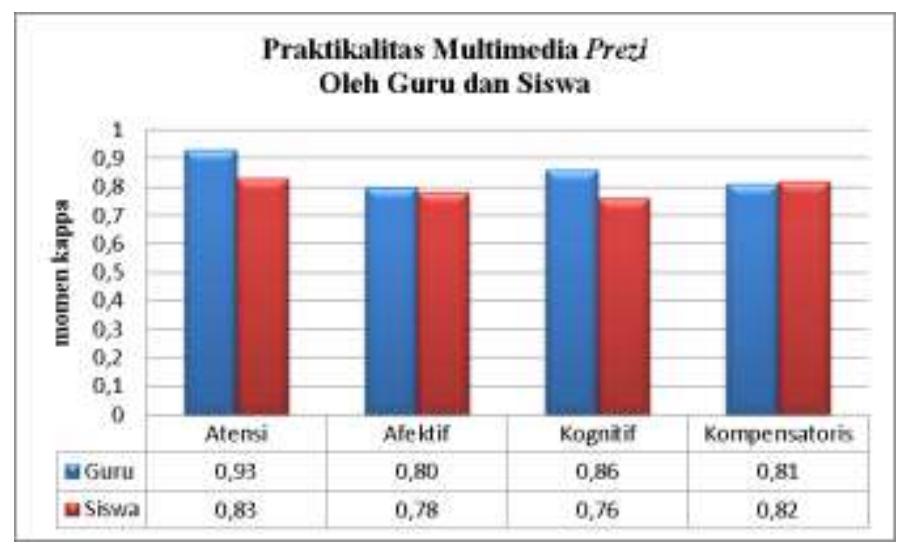

Gambar 3. Hasil analisis data praktikalitas multimedia prezi berbasis Problem Based Learning (PBL) oleh guru dan siswa

\section{B. Pembahasan}

1. Validitas multimedia prezi berbasis Problem Based Learning $(P B L)$

Data validitas multimedia prezi diperoleh dari penilaian 4 orang validator yaitu 2 orang dosen kimia FMIPA UNP dan 2 orang guru kimia SMA. Pemilihan empat orang validator ini didasarkan pada pendapat Sugiyono (2008: 352) yang menyatakan bahwa untuk menguji validitas instrumen, dapat digunakan pendapat ahli yang jumlahnya minimal tiga orang. Penilaian validitas multimedia prezi berbasi PBL didasarkan pada fungsi media yaitu: fungsi atensi, fungsi afektif, fungsi kognitif dsn fungsi kompensatoris dengan uraian sebagai berikut.

\section{a. Fungsi Atensi}

Menurut Levie \& Lentz dalam Arsyad (2007: 16) Fungsi atensi media yaitu menarik dan mengarahkan perhatian siswa untuk berkonsentrasi kepada isi pelajaran. Berdasarkan analisis data penilaian dari validator terhadap fungsi atensi dari multimedia prezi berbasis Problem Based Learning (PBL) dapat nilai momen kappa sebesar 0,86 dengan tingkat validitas sangat tinggi yang menandakan bahwa multimedia prezi berbasis Problem Based Learning (PBL) sudah mampu menarik dan mengarahkan perhatian siswa untuk berkonsentrasi pada materi hukum-hukum dasar kimia yang dipelajari.

Hal ini karena bahasa yang digunakan dalam multimedia prezi berbasis Problem Based Learning (PBL) mudah dimengerti dan sudah sesuai dengan EYD/ kaedah Bahasa Indonesia yang baik dan benar. Dalam pembuatan teks penulis berusaha menggunakan bahasa Indonesia yan baik dan benar agar mudah dimengerti oleh siswa serta informasi yang disampaikan kepada siswa jelas. Proses belajar mengajar adalah proses komunikasi, penyampaian pesan dari pengantar ke penerima (Daryanto,2010:4).

Selain itu, huruf dan ukuran huruf yang digunakan jelas terbaca oleh pengguna, serta gambar yang digunakan sudah jelas, desain dan warna tampilan media yang dikembangkan sudah menarik perhatian siswa. Desain atau gambar yang berwarna dapat menarik perhatian siswa (Sudjana dan Rivai. 2011: 13).

Multimedia prezi berbasis Problem Based Learning (PBL) yang dikembangkan telah memenuhi fungsi atensi dari suatu media sehingga dapat digunakan sebagai media pembelajaran pada materi hukum-hukum dasar kimia dengan tingkat validitas sangat tinggi.

\section{a. Fungsi Afektif}

Menurut Levie \& Lentz dalam Arsyad (2007: 16) Fungsi afektif media dapat terlihat dari tingkat kenikmatan siswa dalam mengikuti pembelajaran terutama dalam mempelajari tulisan yang bergambar. Berdasarkan data penilaian dari validator terhadap fungsi afektif dari multimedia prezi berbasis Problem Based Learning (PBL) didapat nilai momen kappa sebesar 0,90 dengan tingkat validitas sangat tinggi. Hal ini menandakan bahwa multimedia prezi berbasis Problem Based Learning (PBL) mampu senang belajar dan embuat siswa aktif dalam proses pembelajaran.

\section{b. Fungsi Kognitif}

Fungsi kognitif media yaitu media membantu dalam pencapaian tujuan pembelajaran (Levie \& Lentz dalam Arsyad, 2007: 16). Berdasarkan data penilaian dari validator terhadap fungsi kognitif dari multimedia prezi berbasis Problem Based Learning (PBL) didapat nilai momen kappa sebesar 0,86 dengan tingkat validitas sangat tinggi. Hal ini merupakan bahwa materi berupa fakta, konsep dan prosedural yang terdapat dalam multimedia prezi berbasis Problem Based Learning (PBL) telah sesuai dengan kompetensi dasar 3.11 dan 4.11.

Selain itu, materi pada multimedia prezi berbasis Problem Based Learning (PBL) sudah sesuai dengan tujuan pembelajaran yang akan dicapai. Suatu media pembelajaran yang disesuaikan dengan tujuan pembelajaran dan materi pembelajaran layak digunakan sebagai media pembelajaran dalam proses pembelajaran dengan siswa (Sanjaya, 2006:173). Multimedia yang dikembangkan dapat digunakan sebagai media pembelajaran pada materi hukum-hukum dasar kimia dengan tingkat validitas sangat tinggi karena telah memenuhi fungsi kognitif dari suatu media pembelajaran.

\section{c. Fungsi Kompensatoris}

Fungsi kompensatoris media yaitu media yang membantu siswa agar lebih mudah memahami materi pealaran (Levie \& Lentz dalam Arsyad, 2007: 16). Berdasarkan data penilaian dari validator terhadap fungsi kompensatoris dari multimedia prezi berbasi Problem Based Learning (PBL) pada materi hukum-hukum dasar kimia didapat nilai momen kappa sebesar 0,72 dengan tingkat validitas tinggi. Hal ini menandakan bahwa materi 
dan soal-soal latihan yang terdapat dalam multimedia prezi berbasis Problem Based Learning (PBL) mampu membantu siswa yang lemah dalam menerima pelajaran menjadi lebih mudah memahami dan memantapkan konsep terkait materi hukum-hukum dasar kimia. Menurut Hamalik (2008: 95) melalui pemberian latihan akan dapat membantu siswa dalam memantapkan konsep terkait materi yang dipelajari.

Berdasarkan uraian diatas, multimedia prezi berbasis Problem Based Learning (PBL) telah memenuhi fungsi media pembelajaran, yaitu, fungsi atensi, fungsi afektif, fungsi kognitif dan fungsi kompensatoris. Berdasarkan analisis data hasil validasi, multimedia prezi berbasis Problem Based Learning (PBL) memiliki perolehan momen kappa keseluruhan sebesar 0,85 dengan tingkat validitas sangat tinggi. Dengan demikian, media pembelajaran yang dikembangkan sudah sesuai dengan instrumen penilaiannya, serta telah layak digunakan dalam proses pembelajaran. Hal ini sesuai dengan pendapat Sukardi (2011: 31), produk dikatakan valid apabila instrumen dapat mengukur apa yang seharusnya hendak diukur.

Berdasarkan hasil penilaian validator, multimedia prezi berbasis Problem Based Learning (PBL) yang dikembangkan memiliki tingkat validitas sangat tinggi. Walaupun kevalidan media pembelajaran yang dikembangkan sudah sangat tinggi, namun masih ada beberapa komponen yang harus diperbaiki menurut saran dari validator. Saran-saran yang diberikan oleh validator untuk perbaikan multimedia prezi berbasis Problem Based Learning (PBL) ini adalah:

1) Menambahkan video dan contoh faktual disetiap materi.

2) Menambahkan submikroskopik pada multimedia prezi.

3) Video perkaratan besi selesai sampai massa karat ditimbang.

4) Menambahkan kegunaan materi dalam kehidupan nyata.

5) Menggabungkan tabel dengan pertanyaan yang berkaitan dengan tabel.

Setelah dilakukan revisi, maka penelitian dilanjutkan pada tahap berikutnya, yaitu uji praktikalitas.

\section{Praktikalitas Multimedia prezi Berbasis Problem Based Learning (PBL)}

Data praktikalitas multimedia prezi berbasis Problem Based Learning (PBL) diperoleh dari 2 orang guru kimia SMA dan 30 orang siswa kelas XI IPA SMAN 1 Bukittinggi. Penilaian praktikalitas multimedia prezi berbasis Problem Based Learning (PBL) oleh guru kimia dan siswa didasarkan pada fungsi media pembelajaran, yaitu fungsi atensi, fungsi afektif, fungsi kognitif dan fungsi kompensatoris. Hasil analisis data dapat dilihat pada gambar 4.

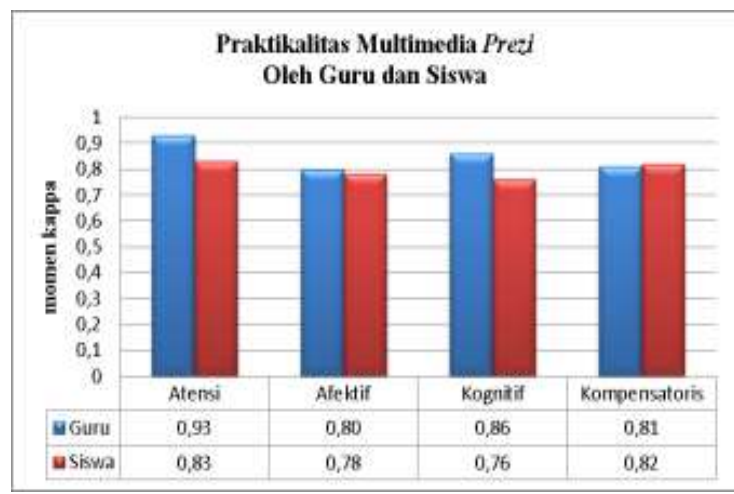

Gambar 4. Hasil analisis data praktikalitas multimedia prezi berbasis Problem Based Learning (PBL) oleh guru dan siswa

Hasil uji praktikalitas oleh 2 orang guru kimia diperoleh rata-rata momen kappa sebesar 0,86 dengan kategori kepraktisan sangat tinggi. Sedangkan hasil uji praktikalitas oleh 30 siswa memiliki rata-rata momen kappa sebesar 0,80 dengan kategori tinggi. Hal ini menunjukkan multimedia prezi berbasis Problem Based Learning (PBL) yang dikembangkan praktis digunakan di sekolah baik dari aspek kemudahan penggunaan, efesiensi waktu dan manfaat media pembelajaran. Kepraktisan sebuah media pembelajaran mempertimbangkan aspek kemudahan penggunaan, penggunaan waktu yang digunakan dalam pelaksanaan, daya tarik media pembelajaran terhadap minat siswa (Sukardi, 2011:52). Maka bisa disimpulkan bahwa multimedia prezi berbasis Problem Based Learning (PBL) praktis digunakan dalam proses pembelajaran.

\section{SIMPULAN}

Berdasarkan penelitian yang telah dilakukan, telah dihasilkan multimedia prezi berbasis Problem Based Learning (PBL) pada materi hukum-hukum dasar kimia menggunakan model pengembangan 4-D. Multimedia prezi yang dihasilkan memiliki tingkat kevalidan sangat tinggi dengan momen kappa 0,85. Praktikalitas oleh guru kimia dengan momen kappa 0,86 dengan kategori sangat tinggi, dan praktikalitas oleh siswa dengan momen kappa 0,80 dengan kategori tinggi.

\section{UCAPAN TERIMA KASIH}

Penulis mengucapkan terima kasih kepada Bapak Dr. Rahadian Z, S.Pd, M.Si., Ibu Fajriah Azra, S.Pd, M.Si., Bapak Dr. Hardeli, M.Si., Bapak Drs. Iswendi, M.S., dan Ibu Dra. Syamsi Aini, M.Si, Ph.D., serta semua pihak yang telah membantu dalam penyelesaian penelitian dan penyusunan artikel ini.

\section{REFERENSI}

Arsyad, Azhar. 2007. Media Pembelajaran. Jakarta: PT Raja Grafindo Persada. 
Boslaugh, Sarah \& Watters, Paul A. 2008. Statistics in a Nutshell, a desktopquick reference. Beijing, Cambridge, Famham, Köln, Sebastopol, Taipei, Tokyo: O'reilly.

Daryanto. 2010. Media Pembelajaran, Peranannya Sangat Penting Dalam Mmencapai Tujuan Pembelajaran. Yogyakarta: Gava Media

Hamalik, Oemar. 2012. Kurikulum dan Pembelajaran. Jakarta: PT. Bumi Aksara.

Krause. 2014. Using PREZI-Technology ti promote inquirybased learning on 'bionics'. Germany: University of Bremen. Hlm. 141-150.

Majid, Abdul dan Chaerul Rochman. 2014. Pendekatan Ilmiah Dalam Implementasi Kurikulum 2013. Bandung: PT Remaja Rosdakarya.

Sudjana, Nana dan Ahmad Rivai. 2002. Media Pengajaran. Bandung: Sinar Baru Algensindo.

Sugiyono. 2011. Metode Penelitian Pendidikan Pendekatan Kuantittif, Kualitatif dan $R$ \& D. Bandung: Alfabeta.

Sukardi. 2012. Metodologi Penelitian Pendidikan. Jakarta: PT Bumi Aksara. 